\title{
Physico-chemical properties of dehydrated seriales (Flacourtia jangomas (Lour) Raeusch) as influenced by sugar levels
}

\author{
Heidi P. Paler ${ }^{2}$ and Lynette C. Cimafranca ${ }^{1 *}$
}

\begin{abstract}
Submitted: 8 January 2019 | Accepted: 24 March 2020

Seriales (Flacourtia jangomas (Lour) Raeusch) is a wild and underutilized fruit growing in rural areas in the Philippines. This study explored the potential of seriales as dehydrated product. A single factor experiment arranged in completely randomized design was undertaken to evaluate the effect of sugar level $(40,50,60$, $70 \& 80 \%)$ on the physico-chemical properties of dehydrated seriales. The procedure in determining the physico-chemical properties of dehydrated seriales fruit follows standard AOAC (1980) procedures. Results revealed that sugar level significantly affects the TSS, pH, moisture content, and water activity of the product.
\end{abstract}

Keywords: dehydrated fruit, Flacourtia jangomas, physico-chemical properties, sugar level

\section{INTRODUCTION}

Seriales (Flacourtia jangomas (Lour) Raeusch) is a wild and underutilized fruit growing in the rural areas in the Philippines and the neighboring countries. Locally, it is known as seriales and sarali. In the neighboring countries, it is called as coffee plum, East Indian plum, Indian plum and Manila cherry (Lim 2013).

The seriales fruit is light green when young, and turns dark-maroon in color when ripe. It contains an appreciable amount of total phenolic compounds of about $306.69 \mathrm{mg} \mathrm{GCE} \cdot 100 \mathrm{~g}^{-1}$ and its fresh fruit has anthocyanin, Vitamin A, Vitamin C, and tannin of about $670.06 \mathrm{mg} \cdot 100 \mathrm{~g}^{-1}, 7.84 \pm 0.11 \mathrm{mg} \cdot 100 \mathrm{~g}^{-1}, 348.93 \pm 5.55 \mathrm{mg} \cdot 100 \mathrm{~g}^{-1}$, $146.80 \mathrm{mg} \mathrm{VE} \cdot 100 \mathrm{~g}^{-1}$, and $32.85 \mathrm{mg} \cdot 100 \mathrm{~g}^{-1}$, respectively (Cimafranca 2017). The antioxidant activity was reported to range from 32.69 to $84.53 \mathrm{mg}$ per $\mathrm{g}$ ascorbic acid equivalents depending on the method of extraction (Cimafranca 2017, Rahman et al 2012, Seal 2014). The fruit contains compounds such as terpenoids,

${ }^{12}$ Department of Food Science and Technology, Visayas State University, Visca, Baybay City, Leyte, Philippines

*Corresponding Author. Address: Department of Food Science and Technology, Visayas State University, Visca, Baybay City, Leyte, Philippines; Email: lynette.cimafranca@vsu.edu.ph DOI: $10.32945 /$ atr4220.2020 
Physico-chemical properties of dehydrated seriales

alkaloids, tannins, lignans and flavonolignans, glucosides, coumarins and isocoumarins as well as xanthones, quinones, limonoids and phenazines as reported by Parvin et al (2011). These various compounds are attributed to the medicinal capability of the plant.

The above chemical compounds serve a range of bio-functional properties including good antioxidant potential which correlates to the fruit's traditional use to treat various health conditions (Rahman et al 2012) such as relief from bronchitis, diarrhea, cough, nausea (Neeharika \& Pandey 2013), a remedy to urinary problems, and skin disease (Quattrocchi 2012), and liver-related disorders (Quattrocchi 2012). However, despite these benefits, seriales fruit remains underutilized and does not receive much attention compared to commercial fruits such as guava, papaya, pineapple (Mohamad 2012) and mangosteen, which are processed in many different ways and are available in various forms. Underutilization of seriales could be due to lack of information about the crop, its nutritional composition, physical qualities, bioactive properties, and the potential benefits of using this fruit. More specifically, studies exploring the potential of the fruit for processing are limited.

Research findings consistently show the effects of processing methods on the resulting product's quality and properties. Jabbar et al (2014), reported significant reduction on the total phenol, flavonoids, tannins, free radical scavenging activity, antioxidant capacity and increased cloud and color values in carrot juice, while pH and acidity increased significantly on the product that has been subjected to acidified blanching method. Cimafranca and Dizon (2017) also revealed that blanching time influenced the sensory acceptability of the ready-to-drink seriales beverage the most. Cimafranca (2017) studied the effect of pre-treatment methods on seriales fruit. Results indicated that various heat treatments such as blanching, steaming, boiling, and microwave cooking on seriales caused significant differences on the proximate composition, vitamin and mineral contents, as well as the physico-chemical properties of the commodity. Hence, this study on the effect of dehydration on the physico-chemical properties of the dried fruit and exploring the potential of seriales fruit as a dried product has been undertaken.

\section{MATERIALS AND METHODS}

\section{Preparation of Raw Material}

The freshly harvested seriales fruits collected from Brgy. Gabas, Baybay City, Leyte were washed and blanched for about one (1) minute. The blanched seriales were then cooled, packed in polyethylene bags, and were subjected to freezing until its use.

\section{Processing of Dried Seriales}

Figure 1 presents the process flow in the production of dehydrated seriales fruit. The first step of the process is the thawing of frozen fruits. Thawed fruits $(500 \mathrm{~g})$ were then cooked for about $3-5 \mathrm{~min}$ in $500 \mathrm{~mL}$ sugar syrup with the amount of 40,50 , 60,70 , and $80 \%(\mathrm{w} / \mathrm{w})$ sugar levels at $75^{\circ} \mathrm{C}$ temperature. It was cooled, and $0.1 \%$ sodium metabisulfite (FAO 2007) was then added. The samples were soaked for $24 \mathrm{~h}$ in the syrup. After soaking, draining of seriales was carried out for $15 \mathrm{~min}$. The 
drained samples were then laid in aluminum screen trays and dried for 8-10h using a cabinet dryer $\left(60^{\circ} \mathrm{C}\right)$. It was then cooled $(5-10 \mathrm{~min})$, wrapped in a clean cheesecloth, and allowed to sweat at ambient temperature in a closed food packaging room for $24 \mathrm{~h}$.

\section{Experimental Design}

A single factor experiment arranged in a completely randomized design (CRD) was used in this study. The variable was sugar level in the soaking solution which was varied in different concentrations namely $40,5060,70$, and $80 \%(w / w)$ as shown in Table 1.

Table 1. Varying levels of sugar concentration in the soaking solution for seriales fruit

\begin{tabular}{cc}
\hline Treatments & $\begin{array}{c}\text { Sugar Level } \\
(\% \mathrm{w} / \mathrm{w})\end{array}$ \\
\hline 1 & 40 \\
2 & 50 \\
3 & 60 \\
4 & 70 \\
5 & 80 \\
\hline
\end{tabular}

\section{Physico-Chemical Analysis}

The physico-chemical properties determined following AOAC (1980) were TSS, $\mathrm{pH}$, moisture content, and water activity.

TSS (Total Soluble Solids). TSS determination was carried out using a calibrated hand refractometer. Dehydrated seriales samples $(15 \mathrm{~g})$ were weighed and homogenized in $60 \mathrm{~mL}$ distilled water. A drop of the sample was placed on the prism, closed, and points the refractometer towards the light source. Then, the value corresponding to the distinct separation in the number line as viewed was read. TSS of the sample was expressed in ${ }^{\circ}$ Brix. The formula used in computing TSS is as follows:

Dilution $=1+($ Volume distilled water $/$ Weight of the sample $)$

$$
\text { TSS }=\text { Dilution Factor } x^{\circ} \text { Brix }
$$

pH determination. Samples $(10 \mathrm{~g})$ collected from each treatment were homogenized with $60 \mathrm{~mL}$ distilled water. The $\mathrm{pH}$ of the prepared sample was measured using a calibrated pH meter (Boeco Germany Model PT-70). Measurements were done in three trials per replication. 
Physico-chemical properties of dehydrated seriales

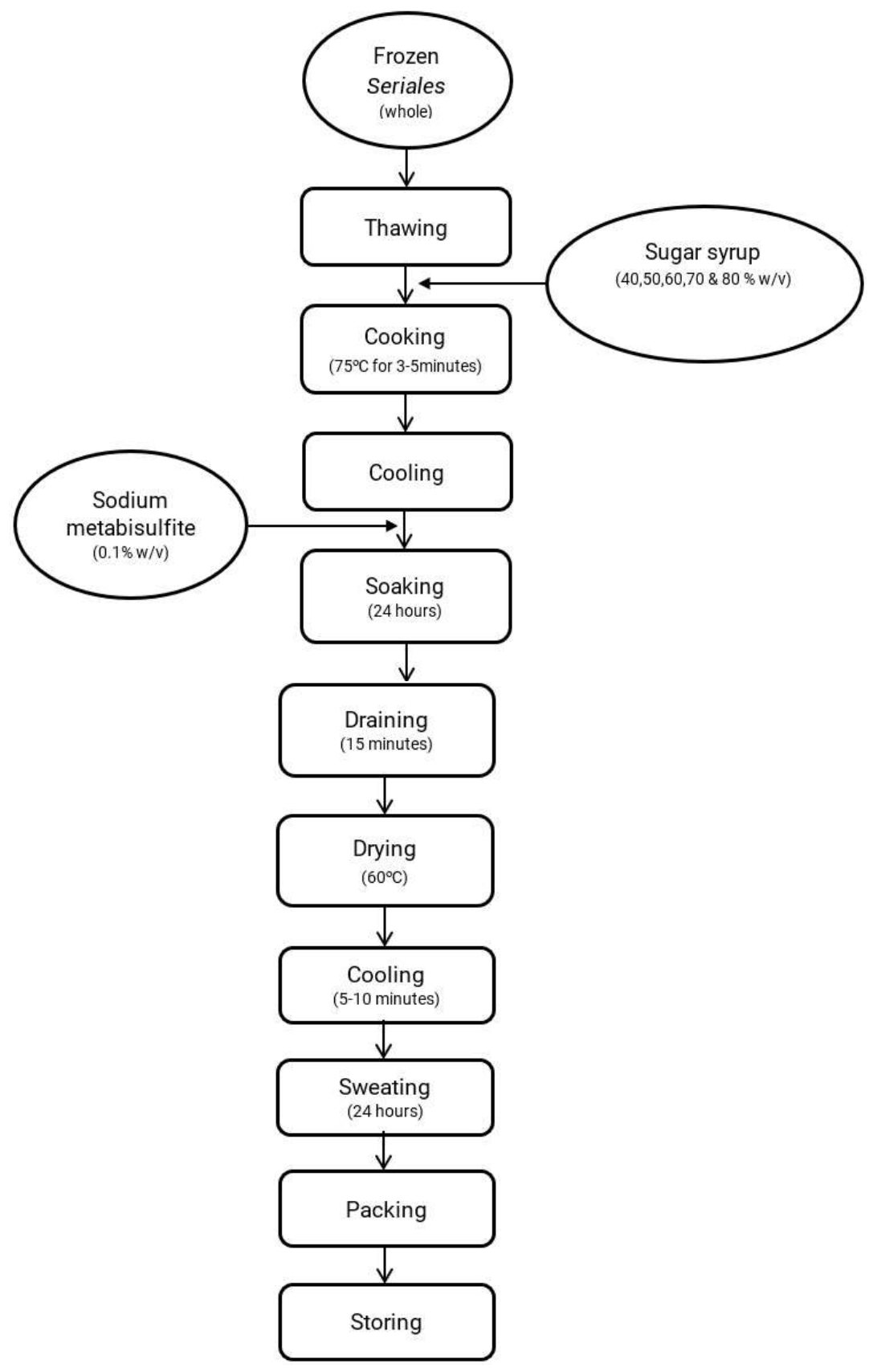

Figure 1. Process flow chart of dehydrated fruit production with modification (Cano 2002) 
Moisture Content (MC) Determination. The moisture content was determined using the oven-drying method. Five (5) grams of finely chopped dehydrated seriales sample were weighed and contained in a moisture dish with predetermined constant weight. The samples were subjected to oven drying at $105^{\circ} \mathrm{C}$ for $24 \mathrm{~h}$, cooled in a desiccator, and weighed. Drying, cooling, and weighing procedure were continued until a constant weight was obtained. The formula used in determining the \% moisture content is as follows:

$$
\begin{aligned}
\text { Moisture }(\%) & =\frac{(B-C)}{A} \times 100, w b \\
\text { Where: } \quad A & =\text { sample weight in g prior to drying } \\
B & =\text { weight of dish }+ \text { sample prior to drying } \\
C & =\text { weight of dish + sample after drying }
\end{aligned}
$$

Aw Measurement. The water activity of dehydrated seriales samples $(5 \mathrm{~g})$ were measured using Smart Water Activity Meter (Model HD-3A), and evaluation was carried out in three (3) replications.

\section{Statistical Analysis}

The data gathered were subjected to One-way Analysis of Variance (ANOVA) using STATISTICA version 8. Significantly different results were further analyzed using Duncan Multiple Range Test (DMRT) to compare treatment means. Average response means were computed using Microsoft Excel 2013.

\section{RESULTS AND DISCUSSION}

\section{Effect on the Total Soluble Solids (TSS)}

One of the most important quality factors for most fruits is the TSS content. According to Malundo et al (2001), chemical measures for sugar levels are standard index for evaluating flavor quality in fruit and vegetables. It does not only represent the sugar content but also the carbohydrates, organic acids, proteins, fats and minerals present, and generally assesses the sweetness of the product. In this study, the TSS values are generally high (Table 2), ranging from 40 to $80 \%$, which most are in agreement with the reports of Bruso (2017) stating that most of the sugar content in dried fruits are incorporated with more than $50 \%$ sugar. Table 2 also shows that TSS contents of dehydrated seriales are directly proportional to the sugar level of the soaking solution, where a significant increase in the TSS was observed as sugar level increases (Table 2). Similar findings were obtained on the study on gingerade by Ocañada (2006).

The seriales fruit soaked at lowest sugar concentration (40\%) revealed to have the lowest TSS value $\left(61.15^{\circ} \mathrm{Brix}\right)$, while sample soaked at $80 \%$ sugar level has the highest TSS value $\left(65.89^{\circ} \mathrm{Brix}\right)$ (Table 2$)$. Comparison between treatments further revealed that $T_{2}$ and $T_{3}$ were not significantly different from each other; also true to $T_{4}$ and $T_{5}$, but the latter treatments were significantly different from the two former treatments mentioned. 
Physico-chemical properties of dehydrated seriales

Table 2. Physico-chemical properties of dried seriales as influenced by varying sugar levels

\begin{tabular}{ccccc}
\hline Treatments & TSS $\left({ }^{\circ} \mathrm{BRIX}\right)^{\star}$ & $\mathrm{pH}^{\star}$ & $\mathrm{MC}(\%)^{\star}$ & $\mathrm{Aw}^{\star}$ \\
\hline 1 & $61.15^{\mathrm{c}}$ & $3.28^{\mathrm{b}}$ & $34.76^{\mathrm{a}}$ & $0.933^{\mathrm{a}}$ \\
2 & $62.19^{\mathrm{b}}$ & $3.21^{\mathrm{b}}$ & $32.87^{\mathrm{c}}$ & $0.908^{\mathrm{b}}$ \\
3 & $61.72^{\mathrm{bc}}$ & $3.20^{\mathrm{b}}$ & $31.52^{\mathrm{cd}}$ & $0.893^{\mathrm{c}}$ \\
4 & $65.72^{\mathrm{a}}$ & $3.29^{\mathrm{b}}$ & $30.74^{\mathrm{d}}$ & $0.884^{\mathrm{d}}$ \\
5 & $65.89^{\mathrm{a}}$ & $3.42^{\mathrm{a}}$ & $27.03^{\mathrm{b}}$ & $0.868^{\mathrm{e}}$
\end{tabular}

$\mathrm{n}=6$; Means with a common letter within a column are not significantly different at $5 \%$ level of significance based on DMRT. ( $T_{1}=40 \%$ sugar level; $T_{2}=50 \%$ sugar level; $T_{3}=60 \%$ sugar level; $T_{4}=70 \%$ sugar level; $T_{5}=80 \%$ sugar level).

\section{Effect on the $\mathrm{pH}$ values}

The intensity of acid in foods is expressed by its $\mathrm{pH}$ value. Dehydrated seriales appeared to be acidic. The acidity of the dehydrated seriales was influenced by the natural acidity of the fruit. According to Cimafranca (2017), the $\mathrm{pH}$ of raw seriales fruit is 3.20 , which is categorically at the acidic range of $\mathrm{pH}$ values. In dehydrated seriales, the $\mathrm{pH}$ values range from 3.20 to 3.42 , which is in agreement with the $\mathrm{pH}$ values reported by Cimafranca (2017), but are comparably lower than $3.64 \pm 0.01 \mathrm{pH}$ obtained on similar fruit from Bangladesh (Ara et al 2014). The highest $\mathrm{pH}$ value was with samples soaked in a solution with the highest sugar concentration. Furthermore, the sample was statistically and significantly different from the rest of the treatment samples. Table 2 also shows that $\mathrm{T}_{3}$ had the lowest $\mathrm{pH}$, but were not significantly different from $\mathrm{T}_{1}, \mathrm{~T}_{2}$, and $\mathrm{T}_{4}$. The sample with the highest level of sugar tended to be less acidic than samples with lower sugar levels, which had similar findings generated by Ocañada (2006) on the study on gingerade.

\section{Effect on Moisture Content (MC)}

Raw seriales fruit contains $72.13 \%$ moisture (Cimafranca 2017). After the drying process, the moisture content of the fruit dropped to about 27.03 to $34.76 \%$ (Table 2). The ANOVA revealed that increased sugar level significantly decreased the moisture content of the product. This finding is in agreement with the findings reported by Kabuo (2014). Comparison between treatment means further revealed that $T_{2}$ was not significantly different from $T_{3}$, but is significantly different from $T_{1}, T_{4}$, and $T_{5}$ (Table 2). Generally, dried fruits are processed containing high levels of sugar. The reduction of moisture content may have been due to increased solids in the product and a reduced amount of free water as sugar content increases. Many other studies reported the significance of low moisture in the dried product, specifically on the objective of improving the keeping qualities of dried foods. Higher moisture content in food generally means there is a higher possibility of microbial proliferation and spoilage. Relating to the results of this experiment, it means that among the treatment samples studied, $T_{5}$ having the lowest moisture 
content may potentially be having a good preservation effect in comparison with the rest of the treatments.

\section{Effect on Water Activity (Aw)}

Water activity is the most important parameter of water in terms of food safety. It is one of the most critical factors in determining the quality and safety of foods. Table 2 shows the mean Aw of every treatment. It shows that the Aw readings range from 0.868 to 0.933 . It further reveals that Aw of dehydrated seriales reduces as sugar level increases and that the five treatment samples were highly significantly different from each other. $T_{5}$ had the lowest water activity. This is influenced by the high level of solute (sugar) added, which has a water binding effect resulting in decreased Aw. A lower Aw is most desirable in the stability of foods, specifically $A w<0.86$ since pathogenic microorganisms mostly are unable to grow at these levels. Among the treatment samples, dehydrated seriales soaked at $80 \%$ sugar level met this quality standard (FAO 2003), therefore could have extended shelf-life over the rest of the treatment samples.

\section{CONCLUSIONS}

Seriales fruit can be processed into a dehydrated product, a product of high value. In processing, sugar concentration in the soaking solution significantly affected the physico-chemical characteristics of the product. Specifically, increasing sugar level significantly decreased the moisture content and water activity of the product, while significantly increasing its TSS value.

\section{ACKNOWLEDGMENT}

The authors thank the Department of Food Science and Technology of the Visayas State University for giving them access to its laboratory facilities.

\section{REFERENCES}

Ara R, Jahan S, Abdullah ATM, Fakhruddin ANM \& Saha BK. 2014. Physico-chemical properties and mineral content of selected tropical fruits in Bangladesh. Bangladesh Journal of Scientific and Industrial Research 49(3):131-136

Association of Official Analytical Chemists. 1980. Official Methods of Analysis. (13th edn). Howitz, Washington DC, USA

Bruso J. 2017. Livestrong. https://www.livestrong.com/article/302660-what-isthe-percentage-of-sugar-in-dried-fruits/

Cano L. 2002. Effects of Sugar Levels on the Drying Rates and Sensory Qualities of Sweetened Mango (BS thesis). Leyte State University, Philippines

Cimafranca L. 2017. Physico-chemical properties, phytochemical components, antioxidant and antimicrobial activities of fresh and processed seriales [Flacourtia jangomas (Lour) Raeusch] fruit (PhD dissertation). University of the Philippines Los Baños, Philippines

Cimafranca $L$ and Dizon E. 2018. Process optimization for sensory characteristics of seriales (Flacourtia jangomas) ready-to-drink (RTD) beverage. IOP Conference Series Earth and Environmental Science 102(1):012071 
Physico-chemical properties of dehydrated seriales

Food Agriculture Organization (FAO). 2003. Handling and Preservation of Fruits and Vegetables by Combined Methods for Rural Areas. FAO Agricultural Services Bulletin 149:75-78. Food and Agriculture Organization of the United Nations, Rome

Food Agriculture Organization (FAO). 2007. Information on Post-Harvest Operations. Storage protection and postharvest physiology. Food and Agriculture Organization of the United Nations

Jabbar S, Muhammad A, Wu T, Hashim MM, Hu B, Lei S, Zhu X \& Zeng X. 2014. Study on combined effects of blanching and sonication on different quality parameters of carrot juice. International Journal of Food Science and Nutrition 65(1):28-33

Kabuo N, Onuegbu NC, Nwosu J, Peter-Ikechukwu Al, Udeozor LO \& Howells-Nworie IC. 2014. Effects of Sugars on the Drying Of Some Local Fruits and Their Importance on Baked Products-Bread and Cake. IOSR Journal of Environmental Science, Toxicology and Food Technology 8(3):99-106

Lim TK. 2013. Flacourtia jangomas. In Edible Medicinal and Non-Medicinal Plants . Springer Netherlands

Malundo TMM, Shewfelt RL, Ware GO \& Baldwin EA. 2001. Sugars and acids influence flavor properties of mango (Mangifera indica). Journal of American Society for Horticultural Science 126(1):115-121

Mohamad AB. 2012. Nutrient composition and antioxidant properties of 'kerekup" fruit (BS thesis). Universiti Teknologi Mara

Neeharika D and Pandey VN. 2013. Ethnobiological importance of Flacourtia jangomas (Lour.) Raeusch. Trends in Biosciences 6(5):532-534

Ocañada JM. 2006. Effects of acid and sugar levels on the quality and acceptability of 'gingerade' (BS thesis). Leyte State University, Philippines

Parvin S, Kader A, Sarkar GC \& Bin Hosain S. 2011. In-vitro study of antibacterial and cytotoxic properties of Flacourtia jangomas. International Journal of Pharmaceutical Sciences and Research 2(11):2786-2790

Seal T. 2014. Antioxidant activities of some wild vegetables of north-eastern region in India and effect of solvent extraction system. International Journal of Pharmacy and Pharmaceutical Sciences 6(5):315-319

Rahman M, Habib R, Hasan R, Islam AMT \& Khan IN. 2012. Comparative antioxidant potential of different extracts of Flacourtia jangomas Lour fruits. Asian Journal of pharmaceutical and clinical research 5(1):73-75

Quattrocchi U. 2012. CCC World Dictionary of Medicinal and Poisonous Plants: Common Names, Scientific Names, Eponyms, Synonyms, and Etymology. CRC Press Taylor and Francis Group, USA 